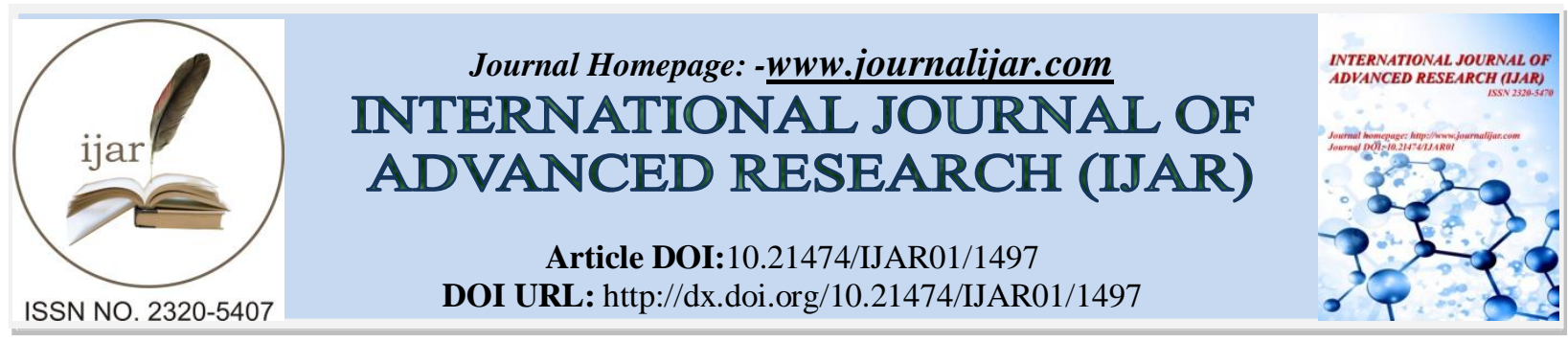

RESEARCH ARTICLE

\title{
A STUDY ON ORGANIZATIONAL CULTURE AND BEHAVIOUR OF EMPLOYEES OF HYUNDAI MOTOR INDIA LIMITED.
}

Dr. A. Arunachala Rajan and Mrs. B. Viji.

Assistant Professors, Department of Commerce,Kamaraj College, Thoothukudi - 628 003, Tamilnadu.

\section{Manuscript Info}

Manuscript History

Received: 16 July 2016

Final Accepted: 22 August 2016

Published: September 2016

Key words:-

Organizational Culture, Behaviour,

Hyundai Motor.

\section{Abstract}

Hyundai Motor India Limited [HMIL] is a wholly owned subsidiary of the Hyundai Motor Company in India. It is the 2nd largest automobile manufacturer in India.HMIL currently exports vehicles to more than 110 countries across Europe, Africa, Middle East, Latin America and Asia. It has been the number one exporter of passenger cars for the sixth year in a row in India with a market share of 48 per cent of the total exports of passenger cars from India. The object of this paper is to study the Organizational Culture and Behaviour of Employees of Hyundai Motor India Limited.

Copy Right, IJAR, 2016,. All rights reserved.

\section{Introduction:-}

Automobile Industry produces automobiles and other gasoline-powered vehicles, such as buses, trucks, and motorcycles. The automobile industry is one of the most important industries in the world, affecting not only the economy but also the cultures of the world. It provides jobs for millions of people, generates billions of dollars in worldwide revenues, and provides the basis for a multitude of related service and support industries. Automobiles revolutionized transportation in the $20^{\text {th }}$ century, changing forever the way people live, travel, and do business.

The automobile has enabled people to travel and transport goods farther and faster, and has opened wider market areas for business and commerce. As a result of easier and faster transportation, the United States and world economies have become dependent on the mobility that automobiles, trucks, and buses provide. This mobility allowed remote populations to interact with one another, which increased commerce. The transportation of goods to consumers and consumers to goods has become an industry in itself. The automobile has also brought related problems, such as air pollution, congested traffic, and highway fatalities. Nevertheless, the automobile industry continues to be an important source of employment and transportation for millions of people worldwide.

\section{Automobile Dealers Network in India:-}

In terms of Car dealer networks and authorized service stations, Maruti leads the pack with networks and workshops across the country. The other leading automobile manufacturers are also trying to cope up and are opening their service stations and dealer workshops in all the metros and major cities of the country. Dealers offer varying kind of discount of finances who in turn pass it on to the customers in the form of reduced interest rates. Government has liberalized the norms for foreign investment and import of technology and that appears to have benefited the automobile sector. 


\section{Profile of Hyundai Motors India Limited:-}

Hyundai Motor India Limited (HMIL) is a wholly owned subsidiary of Hyundai Motor Company, South Korea and is the second largest and the fastest growing car manufacturer in India.

Hyundai Motor India Limited was formed in 6 May 1996 by the Hyundai Motor Company of South Korea. When Hyundai Motor Company entered the Indian Automobile Market in 1996, the Hyundai brand was almost unknown throughout India. During the entry of Hyundai in 1996, there were only five major automobile manufacturers in India, i.e. MUL, HM, PAL, TELCO and M\&M. Daewoo had entered the Indian automobile market with Cielo just three years back while Ford, Opel and Honda had entered less than a year back.

HMIL's first car, the Hyundai Santro was launched in 23 September 1998 and was a runaway success. Within a few months of its inception HMIL became the second largest automobile manufacturer and the largest automobile exporter in India. Hyundai Motor India Limited (HMIL) is a wholly owned subsidiary of Hyundai Motor Company (HMC), South Korea and is the largest passenger car exporter and the second largest car manufacturer in India. HMIL presently markets 6 models of passenger cars across segments. The A2 segment includes the Santro, i10,eon and the i20, the A3 segment includes the Accent and the fluidic Verna and the fluidic elantra, the A5 segment includes the Sonata Transform and the SUV segment includes the Santa Fe.

HMIL has set up a research and development facility in the cyber city of Hyderabad. As HMC's global export hub for compact cars, HMIL is the first automotive company in India to achieve the export of 10 lakhs cars in just over a decade. HMIL currently exports cars to more than 120 countries across EU, Africa, Middle East, Latin America, Asia and Australia. It has been the number one exporter of passenger cars of the country for the sixth year in a row.

HMIL has two manufacturing plants in Sriperumbudur, Kanchipuram district, Tamil Nadu capable of producing 6, 70,000 vehicles annually.

Sales and Services of Network:-

HMIL has 449 dealers and more than 1,150 Service Points across India. HMIL also operates its own dealerships known as Hyundai Motor Plazas in large metros across India. HMIL has the second largest sales and service network in India after Maruti Suzuki.HMIL currently exports vehicles to more than 110 countries across Europe, Africa, Middle East, Latin America and Asia. It has been the number one exporter of passenger cars for the sixth year in a row in India.

Annual sales of Hyundai Motor India Limited:-

\begin{tabular}{|c|r|r|r|}
\hline YEAR & DOMESTIC SALES & EXPORTS & \multicolumn{1}{|c|}{ TOTAL } \\
\hline 1998 & 8,447 & 0 & 8,447 \\
\hline 1999 & 17,627 & 20 & 17,647 \\
\hline 2000 & 82,896 & 3,823 & 86,719 \\
\hline 2001 & 87,175 & 6,092 & 93,627 \\
\hline 2002 & $1,02,806$ & 8,245 & $1,11,051$ \\
\hline 2003 & $1,20,325$ & 30,416 & $1,50,741$ \\
\hline 2004 & $1,39,759$ & 75,871 & $2,15,630$ \\
\hline 2005 & $1,56,291$ & 96,560 & $2,52,851$ \\
\hline 2006 & $1,86,174$ & $1,13,339$ & $2,99,513$ \\
\hline 2007 & $2,00,411$ & $1,26,749$ & $3,27,160$ \\
\hline 2008 & $2,45,397$ & $2,43,919$ & $4,89,316$ \\
\hline 2009 & $2,89,863$ & $2,70,017$ & $5,59,880$ \\
\hline 2010 & $3,56,717$ & $2,47,102$ & $6,03,819$ \\
\hline 2011 & $3,73,709$ & $2,42,330$ & $6,16,039$ \\
\hline 2012 & $3,91,276$ & $2,50,005$ & $6,41,281$ \\
\hline
\end{tabular}

Source : Sales Report of Hyundai Motors India Limited

In 2015Calendar Year, 4, 67, 000cars are sold which is $17.1 \%$ of market share. 
As a part of its social responsibility programs, the company conducts various campaigns to spread awareness of incar safety and safe driving practices, particularly targeted against drunken driving, speeding, etc. As a part of its community development projects, the company has adopted a few villages around its factory in Tamil Nadu and has been working towards the social and economic development of these villages, assisting them in the areas of primary health care, basic amenities and employment opportunities.

\section{Objectives of the Study:-}

This study is undertaken with the following objectives;

1. To assess the existing culture of the organization and to find its impact on employees' behavior of Hyundai Motors India Limited [HMIL].

2. To analyze the overall performance of the employees of HMIL.

3. To learn the employees relationship with their peers.

4. To study the employees feel about the management.

5. To understand how the employer encourages participation in decision making.

6. To find out the employees motivational factor.

\section{Analysis and Interpretation:-}

The study is descriptive in nature i.e., descriptive research. This includes surveys and fact-finding enquiries of different kinds. The main characteristic of this method is that the researcher has no control over the variables; one can only report what has happened or what is happening. This study involves collection of data from Junior Level Executives.

The universe of the study consists of employees (Junior Level Executives) of Hyundai. Out of the total population, data could be collected from 100 persons.

This study involves collection of primary data from the employees of Hyundai. This survey method is used considering the size of the universe and time factor. Data are collected through structured Questionnaire. Questionnaire has been designed and personally administered.As the questions generate direct information, the data were analyzed using Statistical tools such as Simple Percentage and Weighted Average.

\section{Weighted Average:-}

Table no. 1:- Opinion about the organizational factors with respect to employees behavioral aspects.

\begin{tabular}{|c|l|c|}
\hline S. No. & \multicolumn{1}{|c|}{ Factors } & Weightage Score \\
\hline 1. & I am highly involved in my work & 4.21 \\
\hline 2. & I have the ability to manage my own work & 4.24 \\
\hline 3. & The people I work with cooperate to get work done & 3.89 \\
\hline 4. & My team members have a good interpersonal relationship with me & 3.80 \\
\hline 5. & My boss consults me on important maters & 3.47 \\
\hline 6. & My skills and abilities are utilized effectively by the company & 3.61 \\
\hline 7. & My capabilities are viewed as an important source of competitive advantage & 3.49 \\
\hline 8. & My work related suggestions are valued & 3.50 \\
\hline 9. & The organization values diversity & 3.67 \\
\hline 10. & There is a clear and consistent set of values & 3.65 \\
\hline 11. & When disagreements occur, I work hard to achieve “win-win" solutions & 3.82 \\
\hline 12. & It is easy for me to reach consensus, even on difficult issues & 3.65 \\
\hline 13. & I feel happy to work with people from other parts of the organization also & 4.07 \\
\hline 14. & It is easy for me to coordinate with different departments of the organization & 4.24 \\
\hline 15. & I respond well to the organizational changes & 4.31 \\
\hline 16. & I continually adopt new and improved ways to do work & 4.06 \\
\hline 17. & The company's current activities reflect a strong focus on clients & 3.79 \\
\hline 18. & I am given a real opportunity to improve my skills in this organization & 3.82 \\
\hline 19. & I view failure as an opportunity for learning and improvement & 3.93 \\
\hline 20. & There is a clear mission that gives meaning and direction to my work & 3.75 \\
\hline 21. & I am clear with the organizations long-term purpose and direction & 3.90 \\
\hline
\end{tabular}




\begin{tabular}{|l|l|l|}
\hline 22. & I have clear idea about my company's goal & 4.07 \\
\hline 23. & I continuously track my progress against the stated goals & 3.95 \\
\hline 24. & I have shared vision of what the organization will be like in the future & 4.12 \\
\hline 25. & Organization's vision creates motivation for me & 3.94 \\
\hline
\end{tabular}

.Source: Primary Data

From the above Table 1, it is clear that most of the respondents gave more weightage for the statement "I respond well to the organizational changes", secondly respondents give more weightage for two statements "I have the ability to manage my own work \& It is easy for me to coordinate with different department of the organization", third weightage for statement "I have a shared vision of what the organization will be like in the future" and the fifth position is for two statements "I feel happy to work with people from other parts of the organization also \& I have clear idea about my company's goal".

\section{Results and Discussions:-}

$>$ Majority (53\%) of the respondents strongly agreed that they are highly involved in their work.

$>$ Sizable number (47\%) of the respondents strongly agreed that they have ability to manage their own work.

$>$ Majority $(65 \%)$ of the respondents agreed that the people they work with are cooperating to get work done.

$>$ Sizable number $(41 \%)$ of the respondents agreed that they have good relationship with other members.

$>$ Half $(50 \%)$ of the respondents are neutral that their boss consult them on important matters.

$>$ Majority (56\%) of the respondents agreed that the company utilizes their skills and abilities effectively.

$>$ A good number (35\%) of the respondents agreed that there is clear and consistent set of values in the organization.

$>$ Sizable number (49\%) of the respondents agreed that they have clear idea about the company's goal.

$>$ Sizable number (48\%) of the respondents agreed that they continuously track their progress against stated goals of the company.

$>$ Sizable number (46\%) of the respondents strongly agreed that they have shared vision on organization's future.

$>$ Majority (57\%) of the respondents agreed that the organization's vision creates motivation for them.

$>$ Most of the respondents gave more weightage for the statement "I respond well to the organizational changes".

\section{Suggestions:-}

* In training programmes practical sessions must receive greater emphasize.

* The management may enhance the frequency of employee's feedback on their Performance.

* Now, only the employees who belong to committees can participate in decision-making. The management may encourage all the employees to participate in decision-making process.

\section{Conclusion:-}

The study about the organizational culture and behavior on employees reveals that the workers were satisfied with their ability, co-operation, team work, involvement, supervisors, utilization of their skills and rewards etc. They are highly satisfied with the current culture of HMIL.

Because of this favourable culture the employees' show positive behaviours like high involvement, highly commitment to the organization, highly motivated and highly flexible to the organizational changes etc.

\section{References:-}

1. Gupta, S.P, Statistical Methods, Sultan Chand \& Company Ltd., New Delhi.

2. www.hyundai.com

3. en.wikipedia.org/wiki/Hyundai_Motor_India_Limited

4. "ArvindSaxena resigns from Hyundai". 23 July 2012. 